\title{
Understanding stakeholder interactions in urban partnerships
}

This is a pre-proof version of this paper. The citation for the final version of the paper is: Le Feuvre, M., Medway, D., Warnaby, G., Ward, K., \& Goatman, A. (2016). Understanding stakeholder interactions in urban partnerships. Cities, 52, 55-65. doi:10.1016/j.cities.2015.10.017 Figures and tables can be found at the end of the document.

\section{Meryl Le Feuvre ${ }^{1}$, Dominic Medway ${ }^{2}$, Gary Warnaby ${ }^{3}, K^{2}$ in Ward $^{4}$ and Anna Goatman $^{5}$}

${ }^{1}$ Digital Trade Marketing Executive

Visit Jersey

Liberation Place

St Helier

Jersey, JE1 1BB, UK

Email: meryl@visitjersey.je

${ }^{2}$ Manchester Business School *

Booth Street West

Manchester

M15 6PB

Email: dominic.medway@mbs.ac.uk

${ }^{3}$ School of Materials

The University of Manchester

Sackville Street Building

Oxford Road

Manchester

M13 9PL

Email: gary.warnaby@manchester.ac.uk

${ }^{4}$ School of Environment, Education and Development

The University of Manchester

Manchester

M13 9PL

Email: kevin.ward@manchester.ac.uk

${ }^{5}$ Manchester Business School

Booth Street West

Manchester

M15 6PB

Email: anna.goatman@mbs.ac.uk

${ }^{*}$ Corresponding author 


\section{Abstract}

This paper aims to better understand urban partnerships through the nature of the interactions between their stakeholders. Following a review of approaches to stakeholder arrangements in urban partnerships, which draws on a variety of literatures, including strategic management, public administration, urban studies and geography, the paper presents results of an action-case study undertaken in an urban partnership context - namely, Houldsworth Village Partnership (HVP) within the Greater Manchester region of the UK. The findings begin by classifying HVP stakeholders along broad sectoral lines, before moving to examine, through a thematic analysis of data, the influences on their interactions in terms of 'process enablers' and 'inhibitors'. This leads to a schema, whereby HVP stakeholder interactions are conceptualized on the dual continua of attitude and behaviour. The schema provides a theoretical contribution by offering an understanding of stakeholders dynamic interplay within an urban partnership context, and a means of classifying such stakeholders beyond their individual/ organizational characteristics or sectoral affiliations. 


\section{Understanding stakeholder interactions in urban partnerships}

\section{Introduction}

Over the last 20 to 30 years, partnership working, as a means of marshalling different stakeholders from the public, private and voluntary sectors to plan and implement regeneration initiatives, has become a key strategy for many urban areas as they attempt to respond to global economic restructuring (Dicken, 2015). In terms of the resulting structure of urban political institutions, partnerships and partnership-like entities have been identified as part of a broader transition from government to governance (Goodwin and Painter, 1996). For cities, this shift has been conceptualized from various perspectives, including urban growth coalitions (primarily in a US context - see Molotch, 1976), new policy networks and urban regimes (see Bassett, 1996). Notwithstanding their differences in emphasis, these theoretical approaches each acknowledge the range of actors involved in urban governance, and there has been a substantial literature which seeks to analyze the composition of urban partnership organizations. Indeed, within this journal alone, discussion of partnerships or partnership-like arrangements within cities across the globe, and their constituent stakeholders, has been a topic of perennial interest (Jain, 2003; Baud \& Dhanalakshmi, 2007; Lowe, 2008; Ng, Wong \& Wong, 2013; Jung, Lee, Yap \& Ineson, 2014; Chou, Tserng, Lin \& Huang, 2015). This interest is mirrored across a number of disciplines, such as geography, politics, public administration, tourism and urban studies (see, for example, Bailey, Bake \& McDonald, 1995; 
Hastings, 1996, 1999; Carley, Chapman, Kirk, Hastings \& Young, 2000; Roberts \& Sykes, 2000; Carter, 2000; Diamond, 2001; Hemphill, McGreal, Berry \& Watson, 2006; Whitehead, 2007; Timur \& Getz, 2008).

This substantive body of work has been concerned with a number of issues; most notably the dimensions and 'architectures' of urban partnership governance structures that provide the processual or ideological contexts for the interactions of the multiple stakeholders within (see, for example, Baud \& Dhanalakshmi, 2007; Coaffee \& Healey, 2003; Whitehead, 2007). Others have suggested that urban partnership working is characterized by lifecycle modes, through which governance structures may develop and evolve (Lowndes \& Skelcher, 1998). Indeed, within a UK urban context, Cochrane (2000: 536) argues that partnership collaboration for tackling urban problems is something "each new policy generation seems condemned to rediscover and identify $[\ldots]$ anew".

By contrast, there has been little research on the interactions of the stakeholders involved in such partnerships, both in terms of their attitudes towards the partnership arrangement itself, and their behavior towards other stakeholders. This is surprising on two counts. First, as demonstrated below, stakeholder interactions have been examined within the broader strategic management literature. Second, the lack of research in this area seems even more notable when considering Hemphill et al.'s (2006: 60) assertion - with reference to earlier work by Purdue (2001) and Hastings (1996) - that government seems less 
interested in the nature of urban partnership organizational arrangements, and more concerned with the "interaction and dynamic" between partners per se.

Acknowledging this lacuna, our paper takes an action-case approach involving observation of, and interviews with, stakeholders to examine their interactions within an urban regeneration partnership located within the UK's Greater Manchester conurbation. The key contribution of the paper is in its development of a conceptual schema, which offers an understanding of stakeholder interactions within this partnership. In particular, building on the ideas of Brand and Gaffikin (2007) in their extensive critique of collaborative planning approaches, our schema indicates that stakeholders in urban partnership arrangements might be encouraged to engage in a more pragmatic form of 'smart pluralism', guided by compromise (resonant with game theory), rather than in 'coercive dominance'. This may require some decoupling of stakeholders' attitudes towards an urban partnership's objectives from their behaviors towards other stakeholders within that given partnership arrangement.

Drawing on a broader strategic management literature, we begin by briefly considering how stakeholders might be classified in terms of their interaction, and consider the relevance of this in urban partnership contexts. To help set the context of the paper, we then discuss contrasting perspectives on urban partnership arrangements, ranging from those that see these as a panacea for addressing urban problems and implementing programmes of urban 
regeneration and renewal, to more critical viewpoints, which view urban partnerships as little more than a cover for preserving existing hierarchies of stakeholder arrangements. The final part of the literature review considers how urban partnership stakeholders might be classified and concludes by recognizing a need to understand such stakeholders in terms of what they do rather than what they are, emphasizing the salience of the stakeholder interaction focus in our paper.

The subsequent methodology section details the research context and the action-case approach employed. Broadly, an action-case combines aspects of case study (Yin, 2013) and action research (Shani \& Pasmore, 1985; Coghlan \& Brannick, 2005). For this paper, the lead researcher had access to the various partnership stakeholders in her capacity as a Knowledge Transfer Partnership (KTP) Associate employed by one of the main stakeholders (for further details see: www.ktponline.org.uk). The findings begin by classifying stakeholders within our case along sectoral and vested interest lines, before moving to examine, through thematic analysis of data, influences on their interactions in terms of 'process enablers' and 'inhibitors', before developing from this a schema of stakeholder interactions. The paper concludes by discussing the importance of dynamic stakeholder interactions in urban partnership contexts, making the case for future work to be done in this field. 


\section{Stakeholder arrangements and urban partnerships}

Defining and classifying stakeholders

Most definitions and classifications of stakeholders emanate from the strategic management literature and are embedded within a firm-centric view of the world. Early efforts are found in the seminal work of Freeman, who identified a stakeholder as "any group or individual who can affect, or is affected by, the achievement of the organization's objectives" (1984: 46). By the 1990s, stakeholder definition and classification became more sophisticated, focusing on various criteria through which the importance of stakeholders to a given organization could be ascertained. These interrelated criteria include relative power (Mitchell, Agle \& Wood, 1997), and resource relationships in terms of inter-dependency and influence (Frooman, 1999; Savage, Nix, Whitehead \& Blair, 1991). Developing this work, Savage et al. (1991) identify four key stakeholder types that emphasize the degree of interactive support a stakeholder exhibits for an organization: 1) the supportive stakeholder (i.e. the 'ideal' stakeholder, who supports the organization's goals and actions); 2) the marginal stakeholder (who is neither highly threatening nor especially cooperative although they have a stake in the organization and its decisions, they are generally not concerned about most issues); 3) the non-supportive stakeholder (i.e. high on potential threat, but low on potential cooperation, and who can be the most distressing for an organization); and 4) the mixed blessing stakeholder (who has an equal potential to threaten and cooperate). 
Compared to a traditional shareholder perspective on commercial enterprises, in which the interests and benefits of the firm as a focal organization are prioritized, a stakeholder orientation implies more overtly bi-directional and mutually beneficial relationships between the organization and other stakeholders (although the organization itself is still arguably central to the purpose of such relationships). This can occur to the extent that there is "no prima facie priority of one set of interests and benefits over another" (Donaldson \& Preston, 1995: 68). Consequently, there is potential for complex networks of stakeholder interaction to emerge, reflecting stakeholders' potentially diverse (Anheier, 2000; Clarkson, 1995; Freeman, 1984; Macedo \& Pinho, 2006) and conflicting (Bruce, 1995; Dartington, 1996) interests; indeed, it is hard to imagine this would not be the case. There has, accordingly, been debate about whether organizational managers are able to satisfy all stakeholders equally (Strong, Ringer \& Taylor, 2001). Such debates are particularly apposite with regard to the urban partnerships often seen in regeneration and renewal contexts (Paddison, 1997; Peck \& Tickell, 1994). In comparison to perspectives emanating from the management literature, where the firm still holds at least some level of centrality in stakeholder activity, the major point of centrality for stakeholders in urban partnerships is the partnership itself - which is often a very diffuse and amorphous agglomeration of groups from public, private and voluntary sectors, with different ethea, mindsets, perspectives, modus operandi etc. This results in an additional level of complexity to any understanding of stakeholder activity and interaction in an urban partnership context. 


\section{Perspectives on urban partnerships}

Urban partnership arrangements are strongly linked to a neo-liberal shift in ways of thinking about, organizing and managing urban space from the mid-1990s onwards, initially in Western contexts (Peck \& Tickell, 1994; Paddison, 1997; Peck, 1995; Shutt, 2000), and latterly beyond (Baud \& Dhanalakshmi, 2007; Chou, Tserng, Lin \& Huang, 2014). The growing popularity of partnership working in urban contexts can be attributed to multiple interrelated factors, not least, a rise of critiques of the monolithic tendencies of big government, and its inability to respond in an agile enough fashion to an increasingly complex, fragmented and dynamic world (Brand \& Gaffikin, 2007); global calls for more sustainable and integrated systems of urban governance from sources such as the 1992 United Nations Conference on Environment and Development (Baud \& Dhanalakshmi, 2007); and political movements such as New Labour in the UK, which promoted partnerships as a way in which urban communities could play a more active role in shaping the destiny of their surrounding social and economic space for positive effect (Whitehead, 2007). Baud and Dhanalakshmi (2007) indicate that the emergence of such arrangements or 'instruments' in many countries has resulted in various terms being used to describe them, including 'multi-stakeholder arrangements', 'public-private partnerships' and 'urban forums'. This reflects what Harris (2003: 2542) has termed "an immensely complicated, variegated and non-standardised world of governance" where cities are concerned. Within a UK context specifically, such developments and shifts in thinking and practices relating to urban space have given rise to plethora of 
acronyms, reflecting a growing diversity of urban partnership forms: CDPs (Community Development Partnerships - see, Lowe, 2008), UDCs (Urban Development Corporations - see Hastings, 1996) and LECs (Local Enterprise Companies - see Hastings, 1996), to name but three.

Some authors have questioned whether the partnership modus operandi represents an advance in urban governance, or the fragmentation of local policy and disorganization of local politics (Bassett, 1996). Building on this, others have been critical of genuineness of urban partnership arrangements. For example, in a UK context, Whitehead (2007) suggests that they are merely a cloak for the old-school hierarchies of big government and neo-coporatism. Similarly, in the realm of urban collaborative planning arrangements, which are rooted in governance structures of synergistic partnership working, Brand and Gaffikin (2007) indicate that a desire to demonstrate consensus outwardly can stifle and 'gloss-over' inter-stakeholder debates and disputes, thereby disenfranchising rather than empowering stakeholders. They suggest a form of 'smart pluralism' may be a means by which multiple stakeholders may interact more effectively and productively in such contexts, and we will reprise the smart pluralism concept in the conclusion to this paper.

\section{Classifying urban partnership stakeholders}

There have been a few detailed attempts to categorize or classify stakeholders within a general urban context, and more specifically within the context of urban 
partnership working. One early exception is Logan and Molotch's (1987) social typology of urban entrepreneurs, which distinguishes between the different types of stakeholders: 1) Serendipitous entrepreneurs are the least active, and are classified as largely passive; 2) Active entrepreneurs seek to second-guess changing land use values and put themselves in the path of the development process; and 3) Structural speculators seek to move along the political and policy process and influence location and development decisions and shape political decisions, making it imperative that they forge close links with those actors who control development decisions. There are some parallels here with Savage et al.'s (1991) strategic management categorization of stakeholders into marginal, non-supportive and supportive types respectively.

Evans (1997), whilst not referring to the term stakeholders specifically, notes that those interests 'shaping' urban centres can be usefully divided into those who produce such spaces (e.g. property owners, developers, retailers, street artists), those who use them (e.g. employees, shoppers, residents, tourists), and those who intermediate them (e.g. local and national government, estate agents, amenity organizations and pressure groups). Evans (1997) also recognizes that interactions occur between these various groups, to the extent that networks are created, which inevitably result in the formation of power and dependency relations. 
However, the most commonly used criterion for categorizing and classifying urban stakeholders is undoubtedly sectoral, relating to whether stakeholders reside in the public, private or voluntary sectors, or a combination thereof. This criterion is used - either implicitly or explicitly - by both practitioner organizations, such as the Association of Town Centre Management (see ATCM, 1996), and scholars (see, for example, Jung et al., 2014; Ng et al., 2013) alike. We suggest that classifying stakeholders by their sectoral affiliation represents a useful starting point in understanding the key actors involved in urban partnerships, and consequently, we initially employ this approach on the case studied within this paper. However, the problem with such classifications is that they focus on stakeholders in terms of what they are and where they come from, rather than what they do. This paper attempts to overcome such shortcomings by also classifying urban stakeholders in terms of their interactions, thereby shifting the focus from being to doing.

\section{Research context and methodology}

The UK-based urban partnership studied below is the Houldsworth Village Partnership (HVP), named after $19^{\text {th }}$ Century industrialist William Houldsworth who originally operated from the area covered by the partnership. The partnership emerged in the mid-1990s with a multi-stakeholder funded project to redevelop mixed-use commercial, residential, retail and leisure space within abandoned Victorian and Edwardian cotton mills (namely, Broadstone Mill, Houldsworth Mill and Victoria Mill). This acted as a catalyst towards the broader 
objectives of brownfield regeneration of the HVP area for an economically sustainable and socially vibrant future (Le Feuvre, 2011). HVP is therefore similar to many other urban redevelopment and regeneration initiatives found in the former industrial sites of UK cities, some of which have been examined in this journal (Couch \& Dennemann, 2000; Short \& Tetlow, 2012).

The partnership's areal remit lies within the Greater Manchester conurbation (population 2.7 million in 2014), and is situated in the Reddish district between the City of Manchester itself and Stockport Metropolitan Borough (one of the 10 local authorities that make up the Greater Manchester city-region), approximately seven miles to the south east of Manchester city centre. Figure 1 indicates the locational context and spatial extent of the study area.

\section{INSERT FIGURE 1 HERE}

The use of the term 'village' within the HVP nomenclature is only significant in the sense that it reflects the partnership's aims to encourage and facilitate human interaction and a sense of community within the regeneration site. As such, it is typical of the 'urban village' epithet. Franklin and Tait state that the origins of the urban village concept:

“...derive from attempts in urban sociology to conceptualize a certain type of urban experience, in which elements of social processes and values 
believed to be typical of rural (village) life, persist within urban areas" (2002: 268).

In the UK, this idea was revitalized during the late 1980s in the wake of government responses to deindustrialization and associated urban economic decline. It should be stressed that our paper does not set out to explore in detail the urban village concept, rather, HVP is merely the case context through which we examine stakeholder interactions within urban partnership arrangements: further insight into the urban village concept can be found elsewhere (see, for example, Aldous, 1992; Biddulph, Franklin \& Tait, 2003, Franklin \& Tait, 2002).

The action-case approach involved two main stages of data collection. The first involved participant observation. This comprised attendance at HVP steering group meetings and engagement in inter-stakeholder communication/ discussions. An advantage of this process arose from a familiarity with partnership stakeholders, developed through the lead researcher's role as a KTP Associate working for one of these. This facilitated rich insight into events and actions within the partnership without creating suspicion (Coghlan \& Brannick, 2005), and reflected the fact that as a participant, or 'insider-researcher', stakeholders' emotions, good- and ill-will, and organizational politics were more likely to be revealed (Herod, 1999).

Journal entries were made to record observational data, facilitating analysis of inter-stakeholder processes and related behavior (McNiff \& Whitehead, 2002). 
Journal data were structured and analyzed according to Schein's (1999) ORJ model (observation, reaction, judgment, intervention). The researcher observed $(O)$, reacted $(R)$ to what was observed, and subsequently developed a number of informed judgments $(\mathrm{J})$ about stakeholder interaction, although this does not do justice to the 'messiness' of this research process. In line with the action research approach, these judgments were then used to intervene (I) in order to make things happen, consistent with the lead researcher's role as a KTP Associate. Observational data collected enabled an interpretive classification of the stakeholders involved in HVP along the lines of their broad public, private or voluntary sector status, and their perceived level of 'vested interest' (after Cleland, 1999) - i.e. their economic and/ or political investment in the partnership. Moreover, journaling carried out over the course of the KTP period facilitated a longitudinal rather than 'snapshot' perspective and interpretation of stakeholder interactions. This contributed to the development of informed avenues for enquiry, and some initial broad and open-ended questions, for interviews in stage two of the data collection process.

This second stage, investigating stakeholder interactions in greater detail, involved 15 face-to-face, key informant, semi-structured interviews. Bourne and Walker (2005: 655) assert interviews are an effective way to track relationships and influences and "to find out who knows who, in what context and the strength of the influence". The preceding participant observation process allowed the lead researcher to identify interview respondents, based on the extent of their 
participation and interaction in partnership processes. Interviews focused on three key avenues of enquiry: 1) which other stakeholders respondents interacted with; 2) the nature of these interactions; and 3) respondents' perceptions of the importance of the interactions. As noted above, initial interview questions were broad and open-ended to allow for respondents to answer freely, and to give scope for further exploration and follow-up questions by the researcher. Typical questions asked were: 1) Given your position in Houldsworth Village, who do you feel you interact with?; 2) What is the nature of these interactions?; 3) How important do you perceive these interactions to be?

In addition, as a form of credibility testing or 'member checking' (Lincoln \& Guba, 1985), interview respondents were asked to comment on the lead researcher's list of stakeholders, classified in terms of their sectoral affiliation and vested interest, developed via the observation process. Interviewees were encouraged to suggest any necessary changes or modifications to this list and classification although most appeared satisfied with it as presented. Moreover, to get further insight into stakeholder interactions within HVP, interviewees were also asked to identify those stakeholders within the researcher's list that they interacted with, and to explain the nature of those interactions.

Analysis of interview transcripts involved an interpretive identification of repetitive concepts and existing theory-related material, and subsequent coding into appropriate themes (Ryan \& Bernard, 2003), relating specifically to the nature 
and context of stakeholder interactions. As a further form of 'member checking', coded transcripts were returned to participants for review and potential amendment, although this process did not appear to reveal any further thematic insight.

Stakeholder identification: broad sectoral and vested interest classification HVP stakeholders are identified in Table 1, whereby they are coded in column 1 into broad sectoral categories, according to public $(\mathrm{Pu})$, private $(\mathrm{Pr})$ or voluntary (Vo) status. Acknowledging the fluidity of some organizational structures emerging from the data, this basic sectoral classification required extension to incorporate two further categories; namely, public-private partnerships (PPP) and public-private-voluntary partnerships (PPVP). This emphasizes the fact that HVP acts as an umbrella body for other local partnership entities, often with a more specific functional remit and spatial scope. It also reflects the potentially palimpsestic nature of urban partnership formations, as indicated in earlier work (see, for example, Peck \& Tickell, 1994).

Following Cleland (1999), Table 1 also characterizes stakeholders according to their 'vested interest', or economic and political investment, in HVP. This determines the shading within Table 1; thus the higher the vested interest the deeper the greyscale. In most cases, except where self-evident, each stakeholder's role in HVP is briefly outlined. 


\section{INSERT TABLE 1 HERE}

Arising from Table 1, a point to note is the large number of HVP stakeholders $(n=60)$. Although some are on the fringes of partnership activity and only marginally involved in any form of partnership interaction, the numbers involved indicates potential challenges in including and satisfying all interests. Only a handful of stakeholders were identified as exhibiting the highest levels of vested interest in the outcome of HVP: e.g. Broadstone Mill (Pr1), Millshomes (Pr2) and Stockport MBC (Pu1), through its associated involvement in the Stockport Business Incubator (PPP1) and the Stockport Sports Trust (PPP2).

Examining these stakeholders from a strategic management perspective would suggest that those with high vested interest will demonstrate higher levels of interactive support for HVP, typical of Savage et al.'s (1991) 'supportive' stakeholder, and reflecting the fact that such stakeholders stood to gain or lose most due to their substantive financial and/ or political investment in the partnership. This also supports Freeman's (1984) notion that stakeholders are motivated by resource commitment or, more simply, self-interest. Nevertheless, initial evidence from the observational data suggested that some stakeholders with an apparently high vested interest might exhibit lower levels of interactive support towards HVP, falling into Savage et al's (1991) categories of 'mixed blessing' or even 'non supportive' stakeholders. Such situations appeared to arise as a result of role duplication. For example, Business Link North West 
(Pu4) replicated many services offered through the University of Manchester Incubator Company (UMIC - Pu2), creating some confusion around Business Link North West's role in HVP and rendering a stakeholder with apparent high vested interest as apparently relatively uninvolved.

Other stakeholders appeared to exhibit much lower levels of interactive support towards HVP, fitting into Savage et al's (1991) 'marginal' category, and reflecting their lower vested interest. For example, many voluntary organizations only had minimal vested interest in HVP. This can be attributed to the fact that such stakeholders were generally not direct, immediate beneficiaries of HVP activity. Usually, their involvement came through one or two pivotal individuals, or partnership 'champions', within their organizations.

In summary, the initial classification of HVP stakeholders, combined with observational findings, suggests that subtle and complex interactional activity might be occurring amongst them. Our subsequent interpretive, thematic analysis of interview data, also informed by the observation and journaling activities undertaken by the lead researcher, shed further light on the nature and context of such interactions.

The influence of process enablers and process inhibitors on urban stakeholder interaction 
Here we suggest that urban stakeholder interactions might be better understood by examining a partnership's modus operandi (specifically HVP), over time. This resonates with Frooman's (1999) notion that relationships between stakeholders are characterized by an action-reaction dynamic to a greater or lesser degree, as stakeholders seek to achieve their own objectives, and/ or work for the greater good, by means of various influencing strategies. In other words, to be a stakeholder is to inevitably engage in an ongoing process, and this is arguably even more important in the urban partnership context where the focal 'organization' is a constellation of different groups rather than a more monolithic business organization. Such processes are, of course, driven by interactions (in this case, human, social, political and economic), and if we are to understand these interactions, we need to identify the factors influencing them, both positively and negatively. Our interpretive analysis of the data indicated that at the broadest level, there was a distinction between process enabling and process inhibiting influences on stakeholder interactions, which could in turn affect partnership working. We move to discuss these in more detail below.

\section{Process Enablers}

In HVP, process enabling influences on stakeholder interactions included access to opportunities, cooperative competition, process efficiencies and process replication.

Access to opportunities 
A key process enabling influence arose from the potential to open up pathways to partnership success. It was identified that this can occur by bringing together stakeholders' distinctive yet complimentary resources (Mackintosh, 1992) to create - and respond to - possible opportunity. For example, in some cases the development of stakeholder interactions within HVP was a prerequisite for securing funding from external bodies. Thus, from Stockport MBC's (Pu1) perspective, formalized interactions with Broadstone Mill (Pr1) enabled both stakeholders to access funding regimes reserved for partnership working, creating binding ties driven by shared priorities (Wolfe \& Putler, 2002). The prime driver for interaction here was the economic imperative to show evidence of collaboration. Gaining greater influence in political processes was also a motivation. As one interviewee explained, working with other stakeholders in the partnership delivered the benefit of proximity to political decision-making:

"They are the people who were in positions to fund, or allow and fund. They are all the main people that have the influence on what the outcome is going to be... Specifically, working with these individuals facilitates the process of obtaining planning for projects." (Interviewee 1, Pr1)

\section{Cooperative competition}

In some cases HVP stakeholders established cooperative working arrangements, even if this meant interacting with existing/ potential competitors, with a view to securing additional benefits for their own organizations. This occurred in one 
instance with Broadstone Mill (Pr1) and Houldsworth Mill Business and Arts Centre (PPP3), where there was inevitably an element of competition and tension between the two as they both provided managed workspace facilities. However, in their desire to cooperate to develop Houldsworth Village as a hub of activity for the creative and digital sectors, they were able to work effectively together.

One interviewee (Pu3) suggested that tensions often occurred because stakeholders were "all chasing the same bits of European [Union] funding". In this sense, whilst access to opportunities (see above) could represent a motive for stakeholder interaction, cooperative competition related to how these opportunities could be realized. The resulting 'co-opetition' supports research by McLaughlin, Osborne and Chew (2009: 36), which suggests that, "network-based organizations... paradoxically compete by collaborating with each other..., in order to lever in information, resources and capabilities."

\section{Process efficiencies}

Another process enabling influence on stakeholder interactions was identified in the efficiencies gained by combining the respective strengths of stakeholders' different sectoral affiliations (e.g. public, private, voluntary). For example, the public sector stakeholder Stockport MBC (Pu1) secured funding for HVP through the UK Government's Local Authority Business Growth Incentives Scheme. This subsequently helped insulate private sector stakeholders, such as Broadstone Mill (Pr1), from some economic realities in the wider business environment, as 
they could benefit from this funding through the partnership arrangement. In turn, this helped assure Bank $X(\operatorname{Pr} 3)$, also from the private sector, of Broadstone Mill's stability as a developer, and increased Broadstone Mill's credibility and negotiation capacity with other stakeholders. Thus, the process efficiencies of working in partnership reduced perceptions of risk, increased the potential of revenue streams, and facilitated greater stakeholder commitment, both towards HVP and between its stakeholders.

\section{Process replication}

The data indicated that process efficiencies could also become replicated over time, thereby facilitating the development of more extensive and complex partnership interactions and collaborations and the palimpsestic nesting of intrapartnership structures. For example, the Houldsworth Village Vision Group (PPVP1), established to encourage other stakeholders to contribute to areal regeneration, was a sub-partnership situated within HVP. The existence of such sub-partnerships and their interactions appeared to increase the chances of attracting additional external funding into HVP, and this, in turn, encouraged further similar sub-partnership structures to form. In this manner, positive partnership achievements and success led to the replication of those processes of stakeholder interaction that had enabled such success to occur. 


\section{Process inhibitors}

Process inhibitors to the establishment of effective partnership interactions can be summarized as insularity, goal misalignment, apathy, role ambiguity and bureaucracy.

Insularity

The data suggested that the actors representing public sector stakeholders, and in particular Stockport MBC (Pu1), exhibited insularity by operating within the confines of their public sector departmental roles and remits. This reflects Peck's (1995) assertion that in public institutions, lines of accountability are limited and sectoral remits constrain activities. It was evident that this may have hindered the development of HVP, in that it discouraged the widest levels of collaborative working and stakeholder interaction, which might have delivered maximum partnership benefits to all. One Stockport MBC employee reflected on this issue in relation to their involvement in HVP:

"It's just because we are so busy with other projects, so we are not really that great at linking to everything else that goes on [in HVP]. But there are probably opportunities there." (Interviewee, Pu1).

\section{Goal misalignment}

Relating to insularity, another identified process inhibitor was goal misalignment, suggesting that the goals of stakeholders within partnership arrangements such 
as HVP can differ markedly. For example, the internal organizational goals of Stockport MBC (Pu1) as a public sector stakeholder were, understandably, geared towards societal improvement, whereas Broadstone Mill's ( $\operatorname{Pr} 1)$ private sector focus was driven primarily by financial gain. One public sector stakeholder interviewed asserted and clearly acknowledged the difference between their 'societal wellbeing' motives for involvement in HVP with those of private sector stakeholders, noting:

"A private sector organization has its own agenda and that is to make money. It's very, very clear, and it is very transparent, and that's fine." (Interviewee, Pu3).

It is suggested that such differences in goals can at best inhibit stakeholder interaction (certainly at the inter-sectoral level), and at worst, create significant tensions in stakeholder interaction, both of which affect partnership efficiency and operation.

\section{Apathy}

Apathy was typically manifest in poor attendance at HVP partnership meetings and/ or a failure to deliver on, or contribute to, agreed goals/ actions. In such situations, the notion of stakeholder interaction and partnership working rapidly deteriorates. The apathy of one stakeholder was often a consequence of their perceived negative experiences with another. In this sense, negativity and 
related apathy, rather like success (see process replication), is contagious. For example, Broadstone Mill (Pr1) had employed Workspace Centres (Pr7) to manage the tenants in their business incubation space. However, Workspace Centres were not empowered to respond to tenants' complaints, resolve their problems or undertake necessary maintenance. As a result, Workspace Centres became de-motivated. In turn, complaints from tenants about the inactivity of Workspace Centres were directed back at Broadstone Mill itself. An employee of Broadstone Mill highlighted how this negativity and resultant apathy had effectively come full circle:

"By failing to respond to problems in a positive way, the management agent [Workspace Centres] has developed a more hands-off approach where they are unresponsive to issues, and tenants are now complaining to us [Broadstone Mill] about them. We should be resolving these problems together." (Interviewee 2, Pr1).

Accordingly, the process inhibitor of apathy appeared to weaken the quality of the interactions and strength of the bonds between partnership stakeholders.

\section{Role ambiguity}

Role ambiguity emerged as a theme from the data that echoed some of the uncertainties over whether the partnership modus operandi represents an advance in urban governance or the fragmentation of local policy and 
disorganization of local politics (Bassett, 1996). It reflected a potential risk that the complexity of organizational mechanisms between and within urban partnerships (and their sub-partnerships) could work against areal regeneration objectives.

The logic here is that the multitude of stakeholders involved in urban partnerships can act as a process inhibitor by cancelling out some process enablers outlined above and creating 'fuzziness' in terms of unclear stakeholder relationships and lack of clarity in stakeholders' responsibilities towards partnership processes. In HVP, for example, the many stakeholders involved led to ambiguity over who was responsible for what. Existing residents and tenants understood that efforts were being made to improve the area, and there was a perception that many groups were doing something, but limited understanding as to what this 'something' was, or who exactly was doing it:

"There are lots of different people, who have lots of different roles with different titles to their name, and you don't know who's who and who is doing what. It is very fuzzy as to who is in charge." (Interviewee, Pr19).

Another stakeholder put it even more simply, saying that: "No one knows what's going on" (Interviewee, Vo2). 


\section{Bureaucracy}

Our thematic analysis also revealed that process inhibitors could be further compounded by the differing experiences and perceptions of bureaucracy amongst HVP stakeholders. For example, some private sector stakeholders perceived an overly bureaucratic culture amongst those from the public sector. Here, differences in processes, and perceived views about the best way(s) to manage inter- and intra-stakeholder operations and communications, created strategic tensions in partnership working. For example, despite the efforts by the Houldsworth Village Vision Group (PPVP1) for their ten year 'masterplan' to be a recognized as a formal contribution to land-use planning for the area, it was asserted by Stockport MBC (Pu1) that it remained an informal document, as the relevant planning policy coverage was already outlined in the Unitary Development Plan. This emphasized the bureaucratic hurdles that regeneration aspirations can suffer as a consequence of differences in stakeholders' working and operating practices, and captured the "inflexible... attenuated [reconstruction and renewal] process" (Paddison, 1993: 342) that stakeholders can potentially endure, as well as the subsequent "difficulties in altering... physical attributes... in line with the changing requirements of place customers" (Warnaby, 2009: 408).

\section{Attitude and behavior in stakeholder interactions}

The findings above suggest that stakeholder interactions within HVP are set in the broader context of process enabling and process inhibiting influences. 
Further insights from the observational and interview data collected, indicate that such influences serve to affect stakeholder interactions within HVP, both in terms of the attitude of a given stakeholder towards the partnership objectives, and their behavior towards other stakeholders. In this section, we first broadly outline the nature of these inter-relationships into a schema of stakeholder interactions in HVP, seen in Figure 2. We then continue by evidencing and examining such inter-relationships through observational and interview data relating to three indicative vignettes involving HVP stakeholders.

\section{INSERT FIGURE 2 HERE}

Interactions between stakeholders are inevitable and essential to any partnership's operation and achievement of its objectives. Indeed, as Lichfield (2000) implies, without stakeholders' interaction and integration, information and experience cannot be exchanged as effectively between them. In such situations, the concept of partnership, at least in terms of its ability to deliver outcomes, effectively disintegrates. However, the schema proposed in Figure 2 indicates that although stakeholder interaction may be good per se, in terms of the fact that it means stakeholders are engaging with each other and that this can lead to partnership outcomes, we suggest that not all stakeholder interactions result in those outcomes being necessarily positive. Drawing on the evidence of HVP, it is suggested that this is because interactions take different forms, relating to: 1) the attitude of a given stakeholder towards overall partnership objectives - which can 
be envisaged on a continuum from supportive to subversive in Figure 2; and 2) a given stakeholder's interactive behavior towards other stakeholders - which lies on a continuum ranging from collaborative to caustic.

Starting with the attitudinal continuum, we propose that supportive attitudes are defined by a stakeholder believing wholeheartedly in partnership objectives and wishing them to be successful. Conversely, subversive attitudes are exhibited by those stakeholders who rebel against the objectives of the partnership and wish it to fail. Somewhere in the middle, we suggest, lie stakeholders exhibiting skeptical attitudes towards partnership objectives, perhaps rooting for success in some, but not necessarily all of them. Turning to the behavioral continuum, collaborative behavior is defined by a stakeholder acting in a positive manner within the partnership through their behavior towards other stakeholders. By contrast, caustic behavior is exhibited by those stakeholders who behave in a negative manner with regard to others. Somewhere in the middle are stakeholders whose behavior within a partnership appears confused, in that they are willing to collaboratively interact in certain circumstances and on certain matters, but on other occasions may be more caustic and less willing/ able to do so. We additionally propose that the attitudinal and behavioral positions of stakeholders on these two continua will be influenced by a variety of process enablers and inhibitors. 
Finally, Figure 2 contends that specific stakeholder interactions may be categorized by their combined position on the two continua of attitude and behavior. Thus, four theoretical interactive positions are suggested: a) defined by a stakeholder's supportive attitude and collaborative behavior; b) defined by a supportive attitude and caustic behavior; c) defined by a subversive attitude and collaborative behavior; and d) defined by a subversive attitude and caustic behavior. These various interactive positions are now illustrated through three vignettes drawn from the data analysis.

The first vignette relates to positions a) and b) in Figure 2. A good example of the former was evident in the initial interaction between the Broadstone Mill $(\operatorname{Pr} 1)$ and Houldsworth Golf Club (Pr16) stakeholders. Broadstone Mill was central in HVP and, in terms of position on the attitude continuum, was fully supportive of the partnership's broad objectives of regenerating the local urban area. On the behavior continuum, specifically when dealing with Houldsworth Golf Club, the initial interaction was also very collaborative. Thus, Broadstone Mill had established contact with the Golf Club, with a view to providing Mill residents with discounted membership. Over time, however, the relationship deteriorated due to territorial disputes concerning mutual land boundaries. Consequently, although the attitude of Houldsworth Mill remained fully supportive of partnership objectives, its behavior when dealing with the Golf Club rapidly deteriorated towards the caustic (position b). 
The second vignette relates to position c), which was evident in the subversive attitude of the Broadstone Mill Shopping Outlet (Pr14) towards the HVP concept, coupled with its collaborative interactions with other key partnership stakeholders, particularly the Outlet's landlords - Broadstone Mill (Pr1) - and its customers (Pr15) - both existing and potential. Critically, in terms of the subversive position on the attitude continuum, the Outlet predated HVP, and its management were relatively dismissive of HVP regeneration objectives and the proposed image for the area, as it sought to attract a range of residents, workers and visitors who were more likely to be at odds with its existing retail offer and loyal, though ageing, customer base. Nevertheless, the Outlet's management continued to behave in an outwardly collaborative manner towards all other stakeholders, on the basis that they may be potential customers, and through a reluctant realization that adapting to the new, younger clientele that HVP was trying to attract might affect the future success of the business:

"We have to move forward but we can't neglect what we have established. Long before we opened seven years ago there was a factory shop on the site. We gained that customer base. Obviously that is our bread and butter, so to speak. We wouldn't ever turn our backs on that. However, equally we want younger people to come in because they are going to be shopping here in 20 years." (Interviewee, Pr14). 
The third vignette exhibits position d), which was evident in the subversive attitude of the traders making up Reddish District Centre Partnership (PPVP4) towards the HVP regeneration objectives, coupled with their generally caustic interactions with other key partnership stakeholders. Traders appeared to have a negative approach and an unwillingness to participate in many activities contributing towards the general good of HVP and the wider Reddish area. One interviewee reflected these issues when commenting on attempts to organize an event for a Christmas lights switch-on:

"We had six stalls for the district centre traders, and it was only five pounds [to participate], but we only got three traders. I went to the local butcher and said 'Are you not having a table? It would be good... Hot sausage rolls and warm mince pies, you'll make a fortune'. He said, 'No, staff don't want to do it'... It was the same thing last year. You can't get them to move to put anything into the community." (Interviewee, PPVP4).

Evidencing of the schema (Figure 2) through the three vignettes raises various additional points. First, although a stakeholder can only occupy a single position at any one time on the attitude continuum (in terms of support - or lack thereof for HVP), it could exhibit multiple positions on the behavior continuum depending on which stakeholder it is dealing with. Thus, some interactions a stakeholder may have could be collaborative, whilst simultaneously others could be caustic. Second, the souring of relations between Houldsworth Mill and the Golf Club, 
described in the first vignette, indicates that inter-stakeholder interactions are dynamic, and influenced by changing configurations of process enablers and inhibitors. In this particular instance, the interaction between these two stakeholders was initially influenced by the process enabler of access to opportunities, in terms of the mutual economic benefits that could be delivered by Broadstone Mill residents enjoying discounted Golf Club membership. The deterioration of this interaction was subsequently affected by the process inhibitor of insularity, with both stakeholders becoming focused on their own agendas in relation to land boundary disputes. A third point is that although on the attitude continuum only one position can be occupied by a stakeholder at any given time, there is nothing stop this position changing over time as a stakeholder's support for - and associated views of - a partnership arrangement and its objectives strengthen or weaken.

\section{Conclusion}

Through a detailed examination of the data emerging from an action-case, incorporating observation of, and interviews with, stakeholders within HVP, this paper has conceptualized a schema which might help better understand stakeholder interactions in urban partnership contexts. In doing this, we acknowledge that claims of wider applicability arising from what is effectively a single case need to be treated with caution and deserve greater empirical validation in other contexts. This caveat aside, it is suggested that stakeholder interactions arising from the influence of process enablers and inhibitors on 
continua (representative of a stakeholder's attitude towards a partnership and its objectives, and its behavior towards other partnership stakeholders), will, in turn, influence the eventual outcome of overall partnership objectives, and potentially the success or failure of the partnership entity itself.

Using continua to conceptualize stakeholder interaction in an urban partnership context could be viewed as problematic, especially where attitudes are concerned. The issue here is that objectives of urban partnerships might not be clear to all relevant stakeholders, as they are not always explicitly or publicly articulated. This contrasts to a more typical organizational context, where corporate objectives are often articulated through mission and vision statements, and subsequently disseminated through structural hierarchies. Put otherwise, the attitude continuum in our schema relies on the fact that stakeholders can at least perceive and understand some, or all, of the objectives for an urban partnership in the first place, as only this awareness allows them to be supportive, subversive or skeptical in relation to them.

However, an advantage of using continua to understand the interactions of stakeholders in urban partnerships is that it provides a means of conveying dynamism. Thus, in our schema, a stakeholder can theoretically occupy shifting and (in the case of behavior) sometimes simultaneously different interactive positions. This, in turn, suggests that classifying urban stakeholders as being of a particular organizational/ sectoral 'type' is problematic. Certainly, where behavior 
is concerned, different recipients of that behavior may have varied views on how they are treated by a particular stakeholder; and where attitudes are concerned, these may change over time. Furthermore, in trying to understand how an urban partnership works (or more critically how it might work better), then examining the shifting, fluid - and sometimes nuanced and paradoxical - interplay of stakeholder interactions is as important as understanding the individual/ organizational characteristics of the stakeholders themselves. Put otherwise, a key point arising from this paper is that efforts to categorize urban partnership stakeholders by their inter-dependency and influence (Savage et al., 1991), or by their entrepreneurial ethos (Logan \& Molotch, 1987), are arguably hampered by regarding stakeholders per se as the unit of analysis, rather than their interaction(s).

Of particular interest here, is that fact that a stakeholder may have generally supportive attitudes towards a partnership's objectives, whilst simultaneously exhibiting confused or caustic behavior towards fellow stakeholders within that same partnership. The commonsense viewpoint might be that collaborative behavior is always preferable. However, Brand and Gaffikin's (2007) extensive theoretical critique of the collaborative planning literature serves to remind us that collaboration may be difficult in an uncollaborative world. Perhaps where urban partnership working is concerned, there is an important lesson here in benefits of decoupling stakeholder attitudes and behaviors to some extent. 
Explained otherwise, provided attitudes towards the partnership are generally supportive, it might not necessarily matter that some of the behavioral interactions between stakeholders remain confused or caustic in achieving this end. This accords with Brand and Gaffikin's implication that it is perhaps better to live with 'social untidiness', and related aspects of conflict within the world (and perhaps even embrace these positively), if it gets a job done, or a task achieved. Certainly, wasting energy on trying to resolve bad blood between urban partnership stakeholders, and build attitudinal buy-in from all, can detract from valuable time spent trying to further partnership objectives. Using Brand and Gaffikin's (2007: 308) language, the focus for successful urban partnerships perhaps needs to move away from either the "transient tranquilizer of avoidance" or the "high-stakes politics of absolute conquest" in inter-stakeholder behaviors, and focus primarily on knowledge exchange between those stakeholders to maximize the chance of positive partnership outcomes. Brand and Gaffikin (2007) term this the 'smart pluralism' approach. It may, understandably, require urban stakeholders to compromise their individual beliefs and values for the greater good, and in this sense the successful coordination of urban partnership structures may have something to learn from game theory, which has been previously highlighted as way of maximizing the efficacy of urban collaborative ventures such as town centre management (e.g. Forsberg, Medway \& Warnaby, 1999). Deeper consideration of game theory approaches in relation to the interactions of urban partnership stakeholders therefore indicates a potentially fruitful channel of both practitioner concern and future research. 
Finally, whilst this paper does not establish a causal link between process enablers and inhibitors and the eventual interactive outcomes of urban partnerships, it does indicate that those with an interest in the success of those partnerships should focus some attention on removing, or at least minimizing, process inhibitors that are more likely to stimulate subversive attitudes, and to a lesser extent caustic behavior. Future research may wish to examine these potential interplays through more deductive means. Ultimately, this paper indicates that how urban stakeholders engage and communicate with each other may be equally, if not more, important than who they are.

\section{Acknowledgements}

The authors would like to thank Graham Bowden from the Cartographic Unit at the University of Manchester for his work on Figure 1. 


\section{References}

Aldous, T. (1992). Urban villages: A concept for creating mixed-use urban developments on a sustainable scale. London: Urban Villages Group.

Anheier, H. K. (2000). Managing non-profit organizations: towards a new approach. Civil Society Working Paper 1, London School of Economics, http://www.Ise.ac.uk/collections/CCS/pdf/cswp1.pdf

ATCM (1996). About town: Balancing the issues of town centre management. London: ATCM.

Bailey, N., Bake, A. \& MacDonald, K. (1995). Partnership agencies in British urban policy. London: UCL Press.

Bassett, K. (1996). Partnerships, business elites and urban politics: New forms of governance in an English City? Urban Studies, 33(3), 539-555 doi: $10.1080 / 00420989650011906$

Baud, D. \& Dhanalakshmi, R. (2006). Governance in urban environmental management: Comparing accountability and performance in multistakeholder arrangements in South India. Cities, 24(2), 133-147 doi: 10.1016/j.cities.2006.11.003

Biddulph, M., Franklin, B. \& Tait, M. (2003). From concept to completion: a critical analysis of the urban village. Town Planning Review, 74(2), 165193 doi: $10.3828 / \operatorname{tpr} .74 .2 .2$

Bourne, L. \& Walker, D. H. T. (2005). Visualising and Mapping Stakeholder Influence. Management Decision, 43(5), 649-660 doi: $10.1108 / 00251740510597680$ 
Brand, R. \& Gaffikin, F. (2007). Collaborative planning in an uncollaborative world. Planning Theory, 6(3), 282-313 doi: 10.1177/1473095207082036

Bruce, I. (1995). Do not-for-profits value their customers and their needs? International Marketing Review, 12(4), 77-84 doi $10.1108 / 02651339510097757$

Carley, M., Chapman, M., Kirk, K., Hastings, A. \& Young, R. (2000). Urban regeneration through partnership: A study of nine urban regions in England, Scotland and Wales. Bristol: The Policy Press.

Carter, A. (2000). Strategy and partnerships in urban regeneration. In P. Roberts \& H. Sykes (Eds.), Urban regeneration: A handbook (pp. 37-58). London, Thousand Oaks, New Delhi: Sage.

Chou, J-S., Tserng, H. P., Lin, C. \& Huang, W-H. (2015). Strategic governance for modeling institutional framework of public private partnerships. Cities, 42(B), 204-211 doi: 10.1016/j.cities.2014.07.003

Clarkson, M. B. E. (1995). A stakeholder framework for analysing and evaluating corporate social performance. Academy of Management Review, 20(1), 92-117 doi: 10.5465/AMR.1995.9503271994

Cleland, D. I. (1999). Project management strategic design and implementation. Singapore: McGraw-Hill.

Coaffee, J. \& Healey, P. (2003). 'My voice: My Place': Tracking transformations in urban governance. Urban Studies, 40(10), 1979-1999 doi: $10.1080 / 0042098032000116077$ 
Cochrane, A. (2000). The social construction of urban policy. In G. Bridge \& S.

Watson (Eds.), A companion to the city (pp. 531-542). Oxford: Blackwell.

Coghlan, D. \& Brannick, T. (2005). Doing action research in your own organisation (2nd ed.). London: Sage.

Couch, C. \& Dennemann, A. (2000). Urban regeneration and sustainable development in Britain: The example of the Liverpool Ropewalks Partnership. Cities, 17(2), 137-147 doi: 10.1016/S0264-2751(00)00008-1

Dartington, T. (1996). Leadership and management: Oedipal struggles in voluntary organizations. Leadership and Organizational Development Journal, 17(6), 12-16 doi: 10.1108/01437739610130537

Diamond, J. (2001). Managing change or coping with conflict? - Mapping the experience of a local regeneration partnership. Local Economy, 16(4), 272-285 doi: 10.1080/02690940110078274

Dicken, P. (2015). Global Shift: Mapping the Changing Contours of the World Economy $\left(7^{\text {th }}\right.$ ed.). London: Sage.

Donaldson, T. \& Preston, L. E. (1995). The stakeholder theory of the corporation: Concepts, evidence and implications. Academy of Management Review, 20(1), 65-91 doi: 10.5465/AMR.1995.9503271992

Evans, R. (1997). Regenerating town centres. Manchester: Manchester University Press.

Forsberg, H., Medway, D. \& Warnaby, G. (1999). Town centre management by co-operation: Evidence from Sweden. Cities, 16(5), 315-322 doi: 10.1016/S0264-2751(99)00029-3 
Franklin, B. \& Tait, M. (2002). Constructing an image: The urban village concept in the UK. Planning Theory, 1(3), 250-272 doi: $10.1177 / 147309520200100304$

Freeman, E. (1984). Strategic management: A stakeholder approach. Boston: Pitman.

Frooman, J. (1999). Stakeholder influence strategies. Academy of Management Review, 24(2), 191-205 doi: 10.5465/AMR.1999.1893928

Goodwin, M. \& Painter, J. (1996). Local governance, the crises of Fordism and the changing geographies of regulation. Transactions of the Institute of British Geographers NS 21 (4), 635-648 doi: 10.2307/622391

Harris, N. (2003). Globalisation and the management of Indian cities. Econmoic and Political Weekly, 38(25), 2535-2543

Hastings, A. (1996). Unravelling the process of 'partnership' in urban regeneration policy. Urban Studies, 33(2), 253-268 doi: $10.1080 / 00420989650011997$

Hastings, A. (1999). Analysing power relations in partnerships: Is there a role for discourse analysis? Urban Studies, 36(1), 91-106 doi: $10.1080 / 0042098993754$

Hemphill, L., McGreal, S., Berry, J. \& Watson, S. (2006). Leadership, power and multisector urban regeneration partnerships. Urban Studies, 43(1), 59-80 doi: $10.1080 / 00420980500388736$ 
Herod, A. (1999). Reflections on interviewing foreign elites: Praxis, positionality, validity, and the cult of the insider. Geoforum, 30(4), 313-327 doi: 10.1016/S0016-7185(99)00024-X

Jain, A. K. (2003). Actioning new partnerships for Indian cities. Cities, 20(5), 353359 doi: 10.1016/S0264-2751(03)00052-0

Jung, T. H., Lee, J., Yap, M. H. T. \& Ineson, E. M. (2014). The role of stakeholder collaboration in culture-led urban regeneration: A case study of the Gwangju project, Korea. Cities, 44, 29-39 doi: 10.1016/j.cities.2014.12.003

Le Feuvre, M. (2011). Understanding stakeholder relationships in marketing the urban village. Unpublished Thesis submitted for the Degree of Master of Philosophy Business Administration, University of Manchester.

Lichfield, D. (2000). Organisation and management. In P. Roberts \& H. Sykes (Eds.), Urban regeneration: A handbook (pp. 228-253). London, Thousand Oaks, New Delhi: Sage.

Lincoln, Y. S. \& Guba, E. G. (1985). Naturalistic inquiry. London: Sage.

Logan, J. \& Molotch, H. (1987). Urban fortunes: The political economy of place. Berkeley: University of California Press.

Lowe, J. S. (2008). Limitations of community development partnerships: Cleveland Ohio and Neighborhood Progress Inc. Cities, 25(1), 37-44 doi:10.1016/j.cities.2007.11.005

Lowndes, V. \& Skelcher, C. (1998). The dynamics of multi-organizational partnerships: An analysis of changing modes of governance. Public Administration, 76(2), 313-333 doi: 10.1111/1467-9299.00103 
Macedo, I. M. \& Pinho, J. C. (2006). The relationship between resource dependence and market orientation: the specific case of non-profit organizations. European Journal of Marketing, 40(5/6), 533-553 doi: $10.1108 / 03090560610657822$

Mackintosh, M. (1992). Partnership: issues of policy and negotiation. Local Economy, 7(3), 210-224 doi: 10.1080/02690949208726149

McLaughlin, K., Osborne, S. P. \& Chew, C. (2009). Relationship marketing, relational capital and the future of marketing in public sector organizations. Public Money and Management, 29(1), 35-42 doi: $10.1080 / 09540960802617343$

McNiff, J. \& Whitehead, J. (2002). Action research: Principles and practice (2nd ed.). London: Routledge Falmer.

Mitchell, R. K., Agle, B. R. \& Wood, D. J. (1997). Toward a theory of stakeholder identification and salience: Defining the principle of who and what really counts. Academy of Management Review, 22(4), 853-886 doi: 10.5465/AMR.1997.9711022105

Molotch, H. (1976). The city as a growth machine: Toward a political economy of place. American Journal of Sociology, 82(2), 309-332

Ng, S. T., Wong, M. W. \& Wong, K. K. W. (2013). A public private people partnerships (P4) process framework for infrastructure development in Hong Kong. Cities, 31, 370-381 doi: 10.1016/j.cities.2012.12.002 
Paddison, R. (1993). City marketing, image reconstruction and urban regeneration. Urban Studies, 30(2), 339-349 doi: $10.1080 / 00420989320080331$

Paddison, R. (1997). Politics and governance. In M. Pacione (Ed.), Britain's cities: Geographies of division in urban Britain (pp. 317-332). London: Routledge.

Peck, J. (1995). Moving and shaking: Business elites, state localism and urban privatism. Progress in Human Geography, 19(1), 16-46 doi: $10.1177 / 030913259501900102$

Peck, J. \& Tickell, A. (1994). Too many partners... the future for regeneration partnerships. Local Economy, 9(3), 251-65 doi: $10.1080 / 02690949408726239$

Purdue, D. (2001). Neighbourhood governance: leadership, trust and social capital. Urban Studies, 38(12), 2211-2224 doi: $10.1080 / 00420980120087135$

Roberts, P. \& Sykes, H. (2000). Urban regeneration: A handbook. London, Thousand Oaks, New Delhi: Sage Publications.

Ryan, G. \& Bernard, H. R. (2003). Techniques to identify themes. Field Methods, 15(1), 85-109 doi: $10.1177 / 1525822 \times 02239569$

Savage, G. T., Nix, T. W., Whitehead, C. J. \& Blair, J. D. (1991). Strategies for assessing and managing organisational stakeholders. Academy of Management Executive, 5(2), 51-75 doi: 10.5465/AME.1991.4274682 
Schein, E. H. (1999). Process consultation revisited: Building the helping relationship. Reading, MA: Addison-Wesley.

Shani, A. B. \& Pasmore, W. A. (1985). Organisation inquiry: Towards a new model of the action research process. In D. D. Warrick (Ed.), Contemporary organisation development: Current thinking and applications (pp. 438-448). Glenview, IL: Scott, Foresman.

Short, M. \& Tetlow, M. F. (2012). City profile: Sunderland. Cities, 29(4), 278-288 doi: 10.1016/j.cities.2010.12.003

Shutt, J. (1990). Lessons from America in the 1990s. In P. Roberts \& H. Sykes (Eds.), Urban regeneration: A handbook (pp. 257-280). London, Thousand Oaks, New Delhi: Sage.

Stone, C. (1989). Regime politics: Governing Atlanta, 1946-1988. Lawrence, KS: University Press of Kansas.

Strong, K. C., Ringer, R. C. \& Taylor, S. A. (2001). THE* rules of stakeholder satisfaction ("timeliness, honesty, empathy). Journal of Business Ethics, 32(3), 219-230 doi: 10.1023/A:1010714703936

Timur, S. \& Getz, D. (2008). A network perspective on managing urban stakeholders for sustainable urban tourism. International Journal of Contemporary Hospitality Management, 20(4), 445-461 doi: $10.1108 / 095961108110873543$

Warnaby, G. (2009). Towards a service-dominant place marketing logic. Marketing Theory, 9(4), 403-423 doi: 10.1177/1470593109346898 
Whitehead, M. (2007). The architecture of partnerships: Urban communities in the shadow of hierarchy. Policy \& Politics, 35(1), 3-23 doi: $10.1332 / 030557307779657685$

Wolfe, R. A. \& Putler, D. S. (2002). How tight are the ties that bind stakeholder groups? Organization Science, 13(1), 64-80 doi: 10.1287/orsc.13.1.64.544

Yin, R. K. (2013). Case study research: Design and methods (5 $5^{\text {th }}$ ed.). Thousand Oaks, CA: Sage. 
Table 1: Houldsworth Village Partnership Stakeholders: Sectoral and vested interest classification

\begin{tabular}{|c|c|c|}
\hline $\begin{array}{l}\text { Sectoral } \\
\text { code }\end{array}$ & Stakeholder title & Role in Houldsworth Village Partnership \\
\hline Pu1 & $\begin{array}{l}\text { Stockport Metropolitan } \\
\text { Borough Council (MBC) }\end{array}$ & Active supporter and funder. \\
\hline Pu2 & $\begin{array}{l}\text { University of Manchester } \\
\text { Incubator Company (UMIC) }\end{array}$ & $\begin{array}{l}\text { Provided services to support incubating } \\
\text { companies. }\end{array}$ \\
\hline Pu3 & $\begin{array}{l}\text { Creative Industries } \\
\text { Development Service (CIDS) }\end{array}$ & $\begin{array}{l}\text { Aimed to reach prospective commercial tenants } \\
\text { (Pr18) and users of Broadstone Mill (Pr1). }\end{array}$ \\
\hline Pu4 & $\begin{array}{l}\text { Business Link North West } \\
\text { (now replaced by GOV.UK) }\end{array}$ & $\begin{array}{l}\text { Provided business advice for commercial } \\
\text { tenants. Representative on partnership steering } \\
\text { group (PPP6). }\end{array}$ \\
\hline Pu5 & $\begin{array}{l}\text { Greater Manchester } \\
\text { Chamber of Commerce }\end{array}$ & $\begin{array}{l}\text { Viewed partnership as an avenue to promote its } \\
\text { business support services. }\end{array}$ \\
\hline Pu6 & $\begin{array}{l}\text { Guinness Northern Counties } \\
\text { Housing Association }\end{array}$ & $\begin{array}{l}\text { Provided } 70 \text { shared ownership units in } \\
\text { Houldsworth Mill. }\end{array}$ \\
\hline Pu7 & $\begin{array}{l}\text { Manchester Digital } \\
\text { Development Agency } \\
\text { (MDDA) }\end{array}$ & $\begin{array}{l}\text { Representative on partnership steering group } \\
\text { (PPP6). }\end{array}$ \\
\hline Pu8 & $\begin{array}{l}\text { Manchester Knowledge } \\
\text { Capital (M:KC) }\end{array}$ & $\begin{array}{l}\text { Representative on partnership steering group } \\
\text { (PPP6). Also sought to attract high-tech } \\
\text { commercial activity to the area. }\end{array}$ \\
\hline Pu9 & $\begin{array}{l}\text { Manchester Inward } \\
\text { Development Agency Service } \\
\text { (MIDAS) }\end{array}$ & $\begin{array}{l}\text { Gateway to attract potential inward investors to } \\
\text { Broadstone Mill (Pr1). }\end{array}$ \\
\hline Pu10 & Manchester Momentum & $\begin{array}{l}\text { Facilitated access for incubation tenants (Pr11) } \\
\text { to other partnership stakeholders. }\end{array}$ \\
\hline Pu11 & Stockport College & $\begin{array}{l}\text { Students took apprenticeships in the Boost } \\
\text { Centre (PPP7) and exhibited in the Open Studios } \\
\text { (Pr4). }\end{array}$ \\
\hline Pu12 & The University of Manchester & $\begin{array}{l}\text { Involved through UMIC (Pu2) and a Knowledge } \\
\text { Transfer Partnership (KTP). }\end{array}$ \\
\hline Pu13 & $\begin{array}{l}\text { University of Manchester } \\
\text { Intellectual Property Centre } \\
\text { (UMIP) }\end{array}$ & $\begin{array}{l}\text { Targeted prospective commercial tenants to } \\
\text { achieve intellectual property commercialization. }\end{array}$ \\
\hline
\end{tabular}




\begin{tabular}{|c|c|c|}
\hline Pu14 & The Agora Project & $\begin{array}{l}\text { EU-funded project for transforming struggling } \\
\text { retail centres. }\end{array}$ \\
\hline Pu15 & Design Initiative & $\begin{array}{l}\text { Agency promoting exhibitions/ events organised } \\
\text { by Open Studios' tenants (Pr4). }\end{array}$ \\
\hline Pu16 & $\begin{array}{l}\text { North West Development } \\
\text { Agency (NWDA) }\end{array}$ & $\begin{array}{l}\text { Funded High Growth Development Programme } \\
\text { available to tenants. }\end{array}$ \\
\hline Pu17 & St. Elisabeth's School & $\begin{array}{l}\text { Educated local students of the improvements } \\
\text { being invested in the area to encourage them to } \\
\text { feel connected. }\end{array}$ \\
\hline Pr1 & Broadstone Mill & $\begin{array}{l}\text { Property includes open studios (Pr4), managed } \\
\text { workspace (Pr19) and manufacturing space } \\
\text { (Pr24). Perceived itself as leading Houldsworth } \\
\text { Village regeneration. }\end{array}$ \\
\hline Pr2 & Millshomes & $\begin{array}{l}\text { Residential property developer in some old mills. } \\
\text { Went into administration in } 2011 .\end{array}$ \\
\hline Pr3 & Bank X & $\begin{array}{l}\text { Provided financial support for various partnership } \\
\text { stakeholders. }\end{array}$ \\
\hline Pr4 & Broadstone Mill Open Studios & $\begin{array}{l}\text { Organizes public exhibitions, vintage fairs and } \\
\text { arts and crafts events. }\end{array}$ \\
\hline Pr5 & Cooders & Contracted architect for Broadstone Mill (Pr1). \\
\hline Pr6 & Vita Construction & $\begin{array}{l}\text { Completed the refurbishment and managed the } \\
\text { redevelopment of mill buildings. }\end{array}$ \\
\hline $\operatorname{Pr} 7$ & Workspace Centres & $\begin{array}{l}\text { Managed the workspace at Houldsworth Mill } \\
\text { Business and Arts Centre (PPP3), and later } \\
\text { appointed to manage incubation facilities (PPP1). }\end{array}$ \\
\hline Pr8 & Barker PR & $\begin{array}{l}\text { Provided PR and marketing support to } \\
\text { Broadstone Mill (Pr1) and some incubation } \\
\text { tenants (Pr11). }\end{array}$ \\
\hline $\operatorname{Pr} 9$ & Encore Homes & $\begin{array}{l}\text { Property agent for Millshomes' (Pr2) residential } \\
\text { apartments. }\end{array}$ \\
\hline Pr10 & G\&M Associates & $\begin{array}{l}\text { Commissioned to research how best to arrange } \\
\text { and develop the facilities in Broadstone Mill (Pr1). }\end{array}$ \\
\hline $\operatorname{Pr} 11$ & Incubation companies & Tenants in Broadstone Mill (Pr1). \\
\hline $\operatorname{Pr} 12$ & $\begin{array}{l}\text { Pivotal Events and Marketing } \\
\text { (PEM) }\end{array}$ & $\begin{array}{l}\text { Provided marketing/PR services to Broadstone } \\
\text { Mill, incubation companies (Pr11) and } \\
\text { Houldsworth Mill Business and Arts Centre } \\
\text { (PPP3). }\end{array}$ \\
\hline Pr13 & Savills & $\begin{array}{l}\text { Estate agency for residential apartment sales at } \\
\text { Millshomes (Pr2). }\end{array}$ \\
\hline
\end{tabular}




\begin{tabular}{|c|c|c|}
\hline Pr14 & $\begin{array}{l}\text { Broadstone Mill Shopping } \\
\text { Outlet }\end{array}$ & $\begin{array}{l}\text { Part of the Broadstone Mill (Pr1) provided retail } \\
\text { offering within Houldsworth Village. }\end{array}$ \\
\hline $\operatorname{Pr} 15$ & $\begin{array}{l}\text { Broadstone Mill Shopping } \\
\text { Outlet consumers }\end{array}$ & \\
\hline Pr16 & Houldsworth Golf Club & $\begin{array}{l}\text { Hosted corporate golf days for larger workspace } \\
\text { tenant organizations (Pr19). }\end{array}$ \\
\hline $\operatorname{Pr} 17$ & General media & $\begin{array}{l}\text { Prompted activities undertaken as part of } \\
\text { Houldsworth Village. }\end{array}$ \\
\hline $\operatorname{Pr} 18$ & $\begin{array}{l}\text { Vernon Mill artists' studio } \\
\text { group }\end{array}$ & $\begin{array}{l}\text { Had influential voice in the future of Houldsworth } \\
\text { Village. }\end{array}$ \\
\hline $\operatorname{Pr} 19$ & Workspace tenants & $\begin{array}{l}\text { Had influential voice in the future of Houldsworth } \\
\text { Village. }\end{array}$ \\
\hline Pr20 & $\begin{array}{l}\text { Broadstone Mill Shopping } \\
\text { Outlet suppliers }\end{array}$ & \\
\hline Pr21 & $\begin{array}{l}\text { Heaton and Houldsworth } \\
\text { Property Company }\end{array}$ & $\begin{array}{l}\text { Responsible for long-term leasehold of mill } \\
\text { space. }\end{array}$ \\
\hline Pr22 & Kingfisher Gym & $\begin{array}{l}\text { Anchor tenant helping fund the development of } \\
\text { Houldsworth Mill. }\end{array}$ \\
\hline Pr23 & Grey Horse Pub & $\begin{array}{l}\text { Pub in Houldsworth Village, encouraged to } \\
\text { develop an environment that would meet the } \\
\text { rising aspirations of existing/ prospective tenants/ } \\
\text { residents. }\end{array}$ \\
\hline Pr24 & Manufacturing tenants & Mainly based in Broadstone Mill (Pr1). \\
\hline Vo1 & Millshomes Residents & $\begin{array}{l}\text { Had critical role in promoting positive word-of- } \\
\text { mouth about Houldsworth Village and raising } \\
\text { aspirations in the area. }\end{array}$ \\
\hline Vo2 & Existing residents/traders & Wanted to see improvements within the area. \\
\hline Vo3 & Friends of Reddish Station & $\begin{array}{l}\text { Interested in the development of Houldsworth } \\
\text { Village, with efforts to re-open the station as a } \\
\text { commuting stop to Manchester. }\end{array}$ \\
\hline Vo4 & Reddish Traders' Association & Exhibited support. \\
\hline Vo5 & Friends of Reddish Baths & $\begin{array}{l}\text { Supported opening of new swimming baths in the } \\
\text { area. }\end{array}$ \\
\hline
\end{tabular}




\begin{tabular}{|c|c|c|}
\hline Vo6 & Community Council & $\begin{array}{l}\text { Sought to engender support for environmental/ } \\
\text { infrastructural improvements. }\end{array}$ \\
\hline Vo7 & Redeye & $\begin{array}{l}\text { Network generating interest from photographers } \\
\text { in taking space in the Broadstone Mill Open } \\
\text { Studios (Pr4). }\end{array}$ \\
\hline \multicolumn{3}{|c|}{ गय, } \\
\hline PPP1 & $\begin{array}{l}\text { Stockport Business Incubator } \\
\text { Community Interest } \\
\text { Company }(\mathrm{CIC})\end{array}$ & $\begin{array}{l}\text { Part of a major plan to diversify economic base of } \\
\text { Houldsworth Village. }\end{array}$ \\
\hline PPP2 & Stockport Sports Trust & $\begin{array}{l}\text { Leisure facility in a re-developed industrial unit } \\
\text { owned by Broadstone Mill (Pr1). }\end{array}$ \\
\hline PPP3 & $\begin{array}{l}\text { Houldsworth Mill Business } \\
\text { and Arts Centre }\end{array}$ & $\begin{array}{l}\text { Accommodated } 70 \text { managed office units, together } \\
\text { with conferencing facilities. }\end{array}$ \\
\hline PPP4 & $\begin{array}{l}\text { Reddish Buildings } \\
\text { Preservation Trust (RBPT) }\end{array}$ & $\begin{array}{l}\text { Sought funding to restore/ preserve buildings and } \\
\text { original features. }\end{array}$ \\
\hline PPP5 & Winning Business Academy & $\begin{array}{l}\text { Provided incubator tenants (Pr11), with advice/ } \\
\text { support. }\end{array}$ \\
\hline PPP6 & $\begin{array}{l}\text { Houldsworth Village Steering } \\
\text { Group }\end{array}$ & $\begin{array}{l}\text { Responsible for driving forward the Houldsworth } \\
\text { Village Partnership (HVP) concept into a } \\
\text { deliverable programme of action. }\end{array}$ \\
\hline PPP7 & Stockport Boost & Facilitated construction trades skills training. \\
\hline PPP8 & Manchester Hi-Tech & $\begin{array}{l}\text { Encouraged establishment of high-tech } \\
\text { organizations within Broadstone Mill (Pr1) } \\
\text { incubator space; disbanded in mid-2009. }\end{array}$ \\
\hline & $\mathbb{W} \mathbb{1}$ & 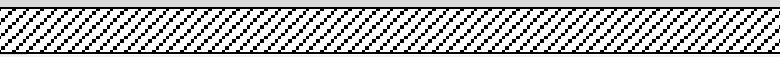 \\
\hline PPVP1 & $\begin{array}{l}\text { Houldsworth Village Vision } \\
\text { Group }\end{array}$ & $\begin{array}{l}\text { Inputted into Houldsworth Village Vision } \\
\text { Masterplan. }\end{array}$ \\
\hline PPVP2 & Hands on Heritage & $\begin{array}{l}\text { Showcased plans for Houldsworth Village through } \\
\text { open Heritage Days. }\end{array}$ \\
\hline PPVP3 & Reddish Crime Panel & $\begin{array}{l}\text { Sought to implement crime reduction measures in } \\
\text { the area. }\end{array}$ \\
\hline PPVP4 & $\begin{array}{l}\text { Reddish District Centre } \\
\text { Partnership }\end{array}$ & $\begin{array}{l}\text { Traders' group aiming to make Reddish (and } \\
\text { Houldsworth Village) a better place to shop. }\end{array}$ \\
\hline
\end{tabular}


Figure 1: Map of study area (Houldsworth Village Partnership)

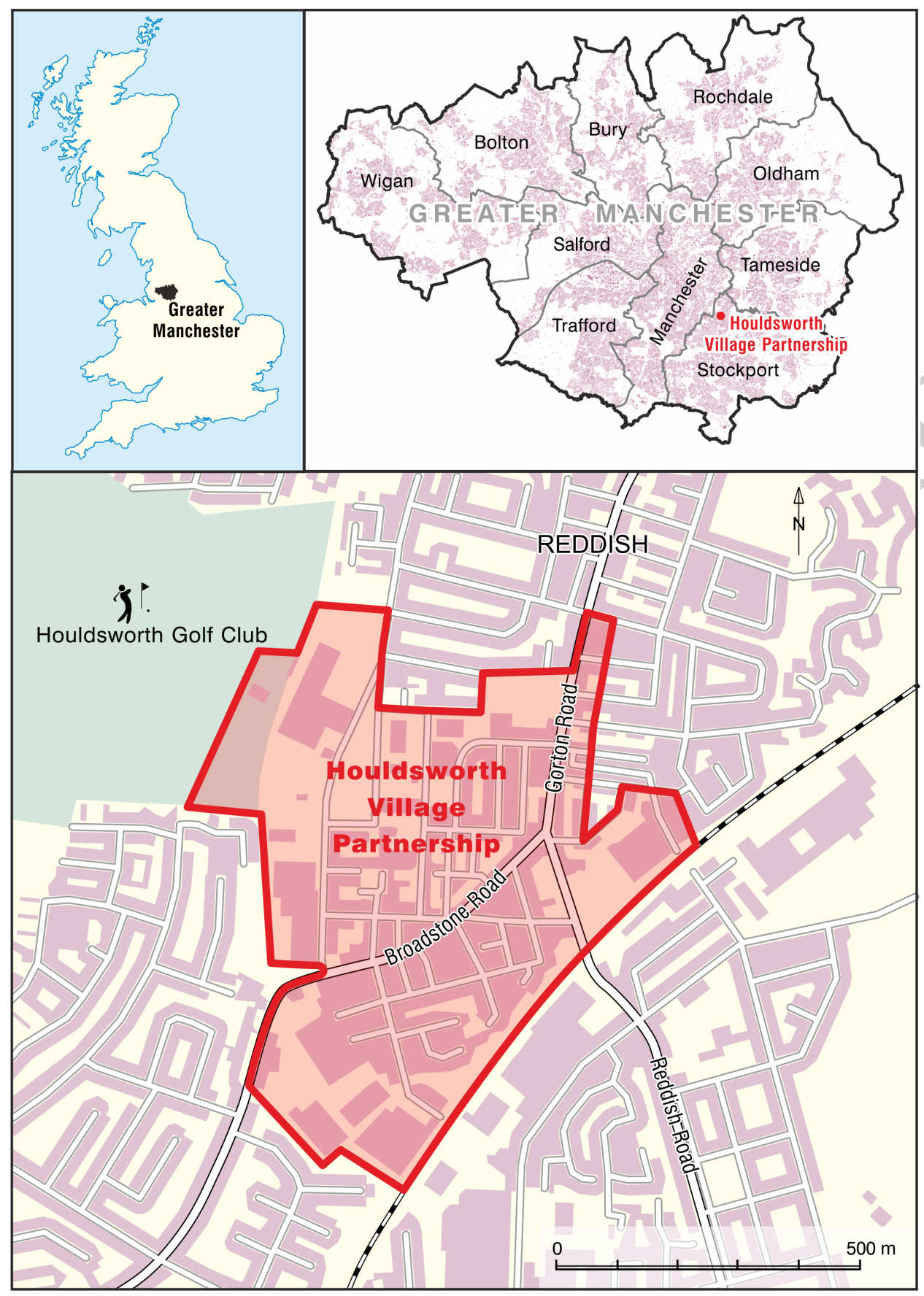


Figure 2: A schema of stakeholder interactions in Houldsworth Village Partnership

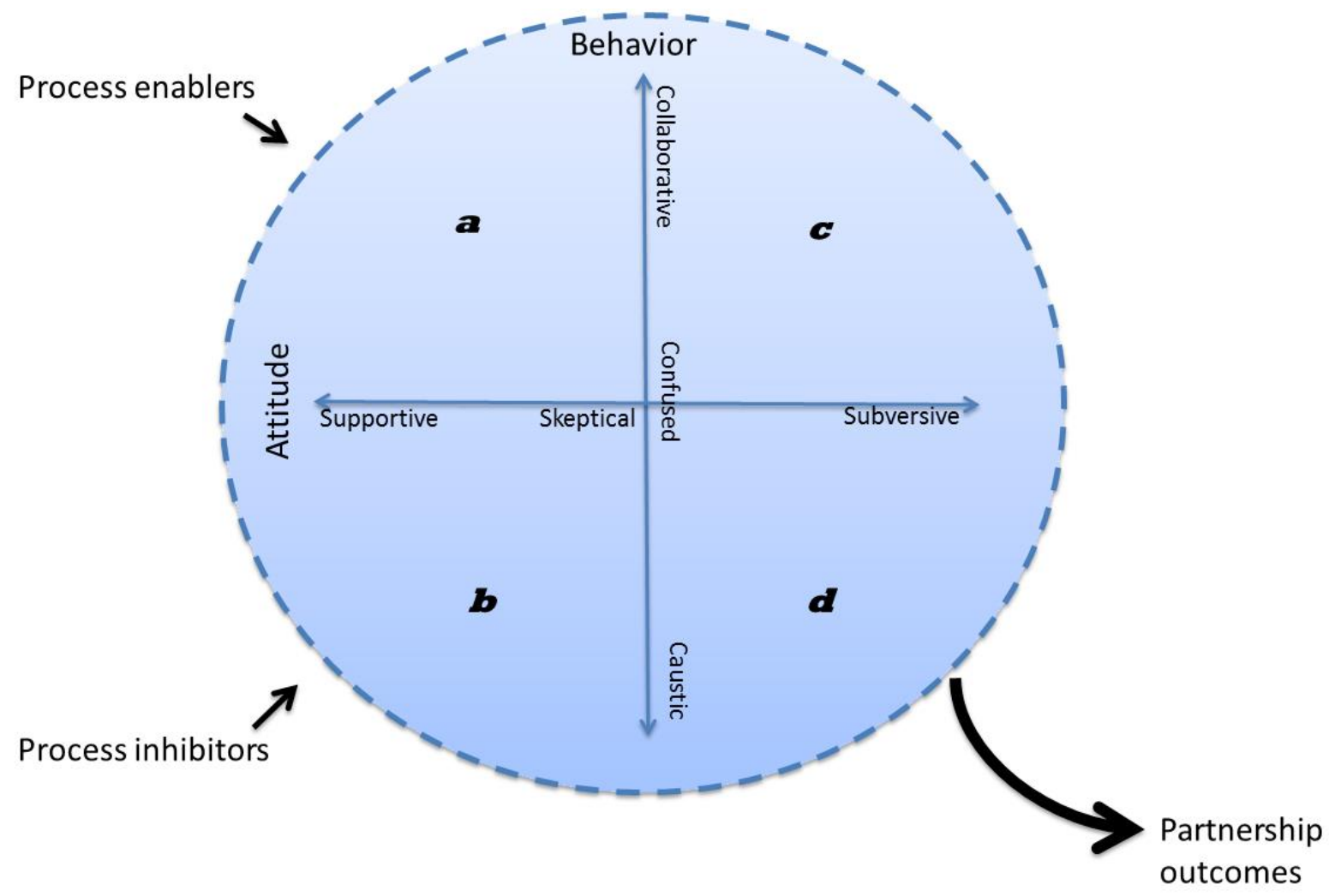

